ЖУКОВСКАЯ Евгения Евгеньевна - кандидат социологических наук, доцент кафедры филологии и журналистики Российского православного университета святого Иоанна Богослова; преподаватель Сретенской духовной семинарии; преподаватель Общецерковной аспирантуры и докторантуры имени свв. Кирилла и Мефодия (127473, Россия, г. Москва, пер. Чернышевского, 11а, стр. 1; evgeniya.press@gmail.com)

\title{
КОНЦЕПЦИЯ СОЗДАНИЯ РЕГИОНАЛЬНЫХ БРЕНДОВ СОВРЕМЕННЫХ РУССКИХ ТРАДИЦИЙ ДЛЯ ИХ ПРОДВИЖЕНИЯ НА МЕЖДУНАРОДНОМ УРОВНЕ
}

\begin{abstract}
Аннотация. Государственная семейная политика, а также программы по воспитанию детей и молодежи нравственно цельными, духовно здоровыми людьми не могут обойтись без темы взращивания в российском обществе любви к русским традициям и национальным устоям. С подобными проектами связано разрешение комплекса региональных проблем в России, таких как развитие и улучшение инвестиционного климата территорий, миграция, сохранение и преумножение колорита народов, проживающих в $P \Phi$.

Осенью 2020 г. в рамках первого этапа программы “Женщина-лидер», организованной мастерской управления «Сенеж» и Советом евразийского женского форума, был подготовлен проект социальной инициативы «Региональный брендинг». Он сосредоточен на двух аспектах проблемы брендирования регионов и формирования презентабельного образа страны за рубежом. В ходе апробации были проведены встречи с жителями районов, малых городов, городов и сел нескольких регионов России, а также с соотечественниками, живущими за рубежом. В результате выработаны рекомендации по созданию новых подходов для продвижения правдивого и положительного образа Российского государства на международной арене через усиление просветительских программ по знакомству с русскими традициями, национальным достоянием российских регионов и жизнью крепких семей граждан России.
\end{abstract}

Ключевые слова: гуманитарное сотрудничество, общественная дипломатия, развитие регионов, традиции, архитектура традиций, региональный брендинг

3 нание своих корней и семейные ценности - основа крепкого государства. Нельзя быть патриотом и уважать свою страну, не зная традиций, устоев, культуры, истории. Невозможно добиться уважения со стороны внешних сил, если граждане не любят свою самобытность и не различают красоту нации. Государственная власть Российской Федерации реализует программы разного уровня, нацеленные на улучшение демографической ситуации, доступности для каждого человека образования, медицины, пакета социальных услуг, на улучшение жилищных условий и качества дорог, поддержку предпринимательства, науки, рост производительности труда. Отдельное внимание уделяется семейной политике и счастливому детству, профилактике социального сиротства.

Забота о семьях и воспитание подрастающих поколений нравственно крепкими является краеугольным камнем политики каждого региона, поскольку от того, насколько местное сообщество стабильно, зависит будущее любой территории. Если люди не знают своих региональных традиций и не привержены национальным устоям, трудно противостоять анархическим настроениям, которые активно вбрасываются в информационное поле буквально каждого гражданина, сложно претворять в жизнь стратегические задачи развития территорий, а также решать проблемы миграции и вымирания малых городов, районных центров, сел, деревень, станиц, кишлаков, хуторов. 
Соединение современного народа России с прошлыми поколениями невозможно проводить только в рамках отведенных нормо-часов в школьных программах, на которых дети узнают, чем кокошник отличается от кушака, а шаровары - от галифе. Многое идет от семьи и тянется из поколения в поколение. Однако уникальность традиций состоит в том, что они трансформируются, сонастраиваются под влиянием времени. И именно этим они живы. Вот почему субъектам РФ в создании региональных брендов недостаточно только открывать краеведческие музеи или организовывать экспозиции, раскрывающие национальные особенности в культурно-просветительских центрах. Неубедительны ряженые в исторические костюмы работники музеев, домов культуры, как тщетны и попытки представить русские традиции только лишь в русских народных сарафанах и в плясках под гармонь.

Региональный брендинг - это визитная карточка региона сегодняшнего дня. А потому он должен включать в себя векторы инновационных технологий и новейших производств, информацию о последнем слове техники и сведения о продолжателях местных традиций. Это не должна быть летопись о делах минувших дней, это жизнь региона по стандартам XXI, а не XIX в.

Такой подход позволяет переосмыслить патриотическое воспитание, формирует новый угол зрения на традиции и на их место в культурно-мировоззренческой парадигме государственной политики. Тем самым укрепляются национальные устои, и у людей возникают внутренние мотивы уважать себя и свою страну. Грамотная стратегия регионального брендинга не только способствует консолидации российского общества, но и прямым образом влияет на позиционирование РФ в своей международной дипломатической миссии. Общество, состоящее из самодостаточных граждан, менее восприимчиво к паразитирующим на сознании фейкам, к введению очередных санкций и попыткам идеологического, экономического, социального воздействия, направленного против целостности страны.

Современное проживание национальных традиций становится не только фундаментом регионального брендинга, но и плацдармом для развития контактов в рамках гуманитарного сотрудничества с российскими соотечественниками, а также гражданами иностранных государств, которые с симпатией относятся к России, ее культуре и ее ценностям. Свидетельством этому могут стать данные Фонда президентских грантов, а также иных благотворительных и грантовых программ федеральных органов исполнительной власти и государственных корпораций, реализующих проекты по общественной дипломатии. Тысячи людей в десятках странах за последние годы через деятельность российских некоммерческих организаций смогли познакомиться с русскими традициями, проникнуться интересом к русскому языку, погрузиться в мир литературы и искусства России. Подобных инициатив с каждым годом все больше, но в геополитическом контексте искажений вокруг России не становится меньше, и потому чем интенсивнее институты гражданского общества будут развивать гуманитарное сотрудничество, тем, с одной стороны, сильнее будет само российское общество (крепче регионы) и, с другой стороны, качественнее информация о России у наших зарубежных партнеров.

Команда «Архитектура традиций»: цели, задачи, целевая аудитория, мероприятия проекта в апробационный период

Под эгидой программы «Женщины-лидеры» в рамках подготовки Евразийского женского форума команда «Архитектура традиций» представила социальную инициативу по созданию регионального брендинга. Пять членов 
команды $^{1}$ подготовили пакет решений по созданию в регионах современного и инновационного паспорта, в основе которого - новое прочтение национальных традиций. Целеполаганием команды стало желание помочь обществу пережить кризис семейных ценностей через обращение к своим корням, чтобы не происходило стирание национальных черт и нивелирование традиционных особенностей регионов России. Возрождение интереса людей к своим корням реально осуществлять через знакомство с региональными, городскими и сельскими традициями местных жителей.

Знакомство широкой аудитории с русскими традициями через продвижение колорита регионов страны - эффективный инструмент гуманитарного сотрудничества. Регионы не могут быть сильными только через реализацию экономических проектов. Инвестиционный климат территорий улучшается, когда местные сообщества, базовым элементом которых являются крепкие семьи, идут в завтрашний день вместе со своими национальными, культурными традициями и устоями.

Цели проекта:

- возвращение интереса к русским национальным традициям в регионах через их осовременивание, а не калькирование прошлого;

- изменение восприятия России на международной арене через перерождение проблематики региональных традиций в России.

Задачи проекта:

- актуализация проблемы изменения формата присутствия темы русских традиций внутри страны и за рубежом;

- разработка новых подходов к продвижению на международном уровне правдивого образа России через популяризацию русских региональных традиций;

- расширение практики гуманитарного сотрудничества институтами гражданского общества.

Целевые аудитории проекта:

В2C: семьи, жители нецентральных городов России;

$B 2 B$ : инфраструктурно ориентированный бизнес, вовлеченный в региональные проекты;

$B 2 G$ : региональные и муниципальные органы государственной власти;

$B 2 S$ : социально ориентированные некоммерческие организации, в т.ч. зарубежные.

С 19 октября по 6 декабря 2020 г. на апробационном этапе проекта прошли 8 мероприятий, в т.ч. 6 публичных (2 проходили в закрытом формате). Проведено свыше 15 встреч с потенциальными партнерами проекта, достигнуты договоренности о поддержке проекта, в т.ч. в рамках организации и проведения мероприятий апробационного этапа. Совокупно в апробации приняли участие свыше 200 чел. (участники мероприятий, представители парт-

\footnotetext{
${ }^{1}$ Елена Глушкова, кандидат юридических наук, доцент, нотариус г. Екатеринбурга; Ксения Дукова, создатель бренда аксессуаров XENIA DUKOVA; Евгения Жуковская, кандидат социологических наук (капитан команды); Екатерина Зефирова, архитектор событий, оператор выставочно-конгрессных и массовых мероприятий, руководитель ООО «Линист»; Алла Ларина, исполнительный директор фонда поддержки гуманитарных и просветительских инициатив «Соработничество».
} 
нерских ведомств и организаций, единомышленники команды «Архитектура традиций» $)^{1}$.

По итогам встреч и мероприятий в 13 городах России, а также в ходе участия в зарубежных мероприятиях партнеров, через обратную связь с партнерами в инстаграм-паблике @arch_of_traditions, в личной переписке и телефонных разговорах подтверждена гипотеза команды проекта о запросе российского общества на новое звучание русских национальных традиций и их фундаментальность для создания регионального брендинга в субъектах РФ. Также подтвердилась гипотеза о необходимости трансформации подходов к продвижению правдивого и положительного образа Российского государства за рубежом через усиление просветительских программ по знакомству с русскими традициями, колоритом российских регионов и жизнью крепких семей граждан России и разработке новых.

\section{Выводы, основанные на информации, полученной от участников апробационных мероприятий}

1. Назрела необходимость пересмотреть подходы к формированию приемлемости Российского государства в геополитическом формате. Сегодня, в т.ч. при проведении в России международных мероприятий планетарного масштаба (Олимпийские игры, Чемпионат по футболу), придумывается новый образ страны - с новыми символами и инновационными традициями, которые не коррелируют с исконными устоями русской нации. С презентацией себя за рубежом дела обстоят еще более плачевно: порой Россия изображается эдаким медведем в косоворотке с балалайкой, причем не всегда в трезвом виде.

2. Русская цивилизация сегодня нередко представляется широкой публике (внутри страны и за рубежом) в виде мультяшных героев с хохломской росписью или в имидже девицы с кокошником, пошитым азиатскими мастеровыми в подвалах российских домов из искусственных тканей. Региональные концепции брендинга нередко игнорируют современный аспект русских традиций: либо транслируется старый, неживой их шаблон, либо придумываются новые символы и образы, которые не имеют никакой связи с местными корнями и данной территорией.

3. Региональный брендинг может стать адекватным ответом в поисках «духов-

1 Мероприятия апробационного периода (до 6 декабря 2020 г.):

- 19 октября 2020 г. - начало публичной презентации команды и ее ценностей через паблик в Инстаграме @arch_of_traditions;

- 2 ноября 2020 г. - установочное совещание команды по реализации социальной инициативы, закрепление территорий для апробационных мероприятий (онлайн);

- 12 ноября 2020 г. - участие в гуманитарной программе «Русские традиции» для соотечественников, проживающих в Болгарии, а также билингвальных семей (онлайн);

- 14 ноября 2020 г. - интервью с членом команды Ксенией Дуковой о проекте и целеполагании для российских СМИ (очное);

- 14 ноября 2020 г. - прямой эфир в Инстаграме (паблик команды @arch_of_traditions) c основательницей бренда русских традиций в одежде (платки) La Moscovite;

- 16 ноября 2020 г. - участие в гуманитарной программе «Русские традиции» для соотечественников, проживающих в Египте, а также билингвальных семей (онлайн);

- 20 ноября 2020 г. - проведение культурно-просветительской программы «Русские традиции» в музее Патриаршества г. Арзамаса (онлайн);

- 24 ноября 2020 г. - проведение правовой программы-дискуссии «Правовые основы крепкой семьи» с жителями нескольких районов Саратовской обл. (онлайн);

- 25 ноября 2020 г. - проведение культурно-просветительской программы «Русские традиции» в Центре русской культуры г. Сарапула (онлайн);

- 14 октября - 05 декабря 2020 г. проведено свыше 15 встреч с потенциальными партнерами проекта, достигнуты договоренности о поддержке проекта, в т.ч. в рамках организации и проведения мероприятий апробационного этапа (очные, онлайн). 
ных скреп» русской нации. Богатство русских традиций мало знакомо нашим современникам. Наблюдается кризис семейных ценностей, искажение восприятия исконно русских национальных установок, упрощение русского символа и обряда, традиций и колорита. Происходит стирание национальных черт и нивелирование традиционных особенностей регионов России. Агломерация русских сел и деревень приводит к потере их самобытности. Миграция людей с малой родины в мегаполисы способствует переплаву многовековых особенностей различных территорий, забвению старинных русских городов и их уклада.

4. Возрождение регионов и укрепление российской государственности невозможно без возвращения к корням. Однако нельзя перенести их в многомерность XXI в. - с его инновациями, быстрым нелинейным развитием, сложными процессами в обществе.

5. Необходимо создать новую архитектуру для перерождения русской ментальности, основанной на мультикультурном и многонациональном характере России. Важно разбудить интерес людей к своим корням через знакомство с региональными, городскими и сельскими традициями местных жителей. В таком случае при создании регионального брендинга не будут вхолостую переноситься мертвые знания о былых достижениях, но появятся предпосылки к перезапуску традиций и промыслов в новейшее время. Это позволит сформировать уважение к предкам и желание стать продолжателями их традиций, но в условиях эпохи XXI в.

6. Геополитический кризис вокруг России, наблюдаемый на протяжении последних 6 лет, требует пересмотра подходов к международному гуманитарному сотрудничеству. Институты гражданского общества способны сегодня предложить государственной власти новые подходы к формированию положительного имиджа России на международной арене и расширению практики общественной дипломатии через культурно-просветительские контакты, нацеленные на знакомство с русскими национальными традициями и русским языком и продвижение их за рубежом.

7. Фактически у государства, занимающего 1/6 часть земного шара, заблокированы возможности ведения честного, открытого и непредвзятого диалога с зарубежными государствами и партнерами, иностранными гражданами. Официальные российские структуры ограничены в реализации своих международных программ и проектов, и единственным способом говорить правду порой становятся неформальные события с участием российских граждан, соотечественников и тех, кто симпатизирует России и ее традиционным ценностям.

8. Знакомство широкой аудитории с русскими традициями через продвижение колорита регионов страны может стать еще одним инструментом гуманитарного сотрудничества по ряду причин:

- региональный брендинг скорее ассоциируется с туризмом и культурой, чем с «мягкой силой» внешней политики;

- знакомство с русскими традициями через региональный брендинг может привлечь внимание выходцев из России (потомков тех, кто когда-то жил на этих территориях), и, тем самым, актуализация традиций будет происходить глубже, в проявлении уважения к своим корням без неадекватной политизации портрета России;

- включение программ регионального брендинга сможет разнообразить традиционные форматы презентации России за рубежом (например, во время форумов, выставок), раскрыть новые аспекты инвестиционной привлекательности регионов для зарубежных партнеров, а также значительно расширить потенциальную аудиторию таких международных площадок за счет привлече- 
ния внимания к ним многочисленных небольших российских и иностранных сообществ.

\section{Финансовая устойчивость проекта}

Проект «Региональный брендинг» нельзя назвать бизнес-проектом; это социальный проект, нацеленный на выявление в регионах активных граждан и соединение их в сообщества вокруг традиционных нравственных ценностей. Однако инициативность институтов гражданского общества и расширение практики реализации их эффективных проектов делает регион устойчивым политически, экономически, социально. В связи с этим у проекта есть перспективы стать успешным и с точки зрения финансового развития.

Экономические перспективы проекта можно разложить на несколько частей: прибыльность для региона; прибыльность для целевых групп; прибыльность для команды.

Прибыльность для региона и для целевых групп взаимосвязаны и складываются из нескольких факторов, среди которых можно выделить развитие внутреннего туризма в небольшие населенные пункты субъекта РФ; создание туристических кластеров (а вместе с ними - новых рабочих мест и инфраструктуры в малых городах и селах); улучшение инвестиционного климата на территориях, удаленных от областного центра, что дает новые точки опоры государственной власти и бизнесу для повышения ряда экономических показателей. Здесь можно привести следующие примеры.

1. Открытие музея русской культуры с возможностью проведения встреч и лекций, просмотров фильмов, с гастрономическими лавками, гостиничными номерами будет способствовать не только приезду на эту территорию туристов, но и формированию положительных настроений среди местных жителей, которые нередко уезжают с малой родины как раз по причине отсутствия досуга и инфраструктуры для жизни в цивилизованном обществе.

2. Проведение ярмарок на этих же территориях, связанных с памятными датами (День славянской письменности и культуры, День семьи, любви и верности, День народного единства, пасхальный и рождественский периоды), позволит местным фермерам, работникам народных промыслов предложить свои товары не только местным жителям, но и гостям города или села. Этим ярмаркам в разных районах области можно придать региональный статус, чтобы на них приезжали региональные власти, проводили на полях их работы культурно-просветительские мероприятия и деловые встречи, а также встречи с общественностью региона. На ярмарки целесообразно приглашать соседей из других регионов. Это не только усилит интеграционные процессы в финансовом плане, но и станет стимулом для культурной, образовательной интеграции между жителями субъектов РФ.

3. Активизация местных общественных институтов будет способствовать насыщению региональных практик поддержки граждан и развитию семейной политики, заложит предпосылки формирования региональных паспортов, содержащих примеры общественных инициатив, рожденных самим народом на основе местных традиций. Подобный опыт можно будет не только представлять на федеральном уровне, но и включать его в международные партнерские программы страны, через которые в регион могут прийти инвестиции зарубежных партнеров.

Прибыльность для команды обусловлена компетентностью членов команды и их профессиональными компетенциями в разных областях и специализациях. Это дает возможность разноаспектно подходить к реализации идей проекта «Региональный брендинг». В команду проекта входят: 
1) эксперт в области развития институтов гражданского общества и организации событий в рамках гуманитарного сотрудничества, эксперт по выстраиванию взаимоотношений между государством и некоммерческим сектором, практикующий социолог (кандидат социологических наук), занимающийся проблематикой внутренней политики и международной миссии через культурно-просветительские программы более десяти лет;

2) эксперт в области социального проектирования, гуманитарного сотрудничества, развития некоммерческого сектора в России, реализации социально значимых инициатив, создания сообществ активных граждан, продвижения добровольчества и волонтерства;

3) архитектор событий, профессиональный оператор выставочно-конгрессных и массовых мероприятий, руководитель медийных проектов международного, федерального и регионального уровней;

4) нотариус, кандидат юридических наук, доцент, член совета регионального отделения Ассоциации юристов России, член международной комиссии Федеральной нотариальной палаты, член международной комиссии Ассоциации юристов России, заместитель председателя методической комиссии Нотариальной палаты своего региона;

5) основательница и генеральный директор бренда аксессуаров, которая одной из первых в стране стала применять традиционные русские узоры и символы в своем творчестве.

Инструменты финансовой стабильности команды «Архитектура традиций»:

- взаимодействие с профессиональными ассоциациями и институтами;

- организация экспозиций регионов на международных площадках;

- создание брендбуков регионов;

- продвижение русских национальных традиций регионов на федеральном уровне ${ }^{1}$;

- консультирование региональных властей по созданию брендов, выявлению гражданской активности ${ }^{2}$, формированию местных сообществ инициативных граждан;

- формирование практики амбассадорства и инфлюенсерства для региональных брендов для дальнейшей презентации на международных площадках;

- формирование заказов на выполнение сувениров, медиапродуктов от партнеров проекта ${ }^{3}$.

1 По итогам проведенных мероприятий в результате знакомства представителей государственной власти с региональными традициями Арзамаса, Сарапула и территорий Заволжья поступили предложения представить их в Совете Федерации и продумать систему поддержки гражданских инициатив на региональном и федеральном уровне.

2 Представители государственной власти Удмуртии и Нижегородской обл. проинформированы о возможных формах поддержки активных граждан, заинтересованных в продвижении русских национальных традиций. Даны рекомендации по подготовке заявок на конкурс Фонда президентских грантов. Инициативы включены в портфель эффективных проектов регионов.

3 К 6 декабря 2020 г. получен заказ на создание серии сувениров из аксессуаров, выполненных в русских национальных традициях. Сувениры планируется распространять в рамках культурно-просветительских мероприятий в России и за рубежом. 
ZHUKOVSKAYA Evgeniya Evgen'evna, Cand.Sci. (Soc.), Associate Professor of the Chair of Philology and Journalism, Russian Orthodox University of St. John the Theologian; Lecturer at the Sretensky Theological Seminary; Lecturer at the Church-wide Standard and Higher Doctorate named after Saints Cyril and Methodius (bld. 1, 11A Chernyshevskogo Lane, Moscow, Russia, 127473; evgeniya.press@gmail.com)

\section{THE CONCEPT OF CREATING REGIONAL BRANDS OF MODERN RUSSIAN TRADITIONS FOR THEIR PROMOTION AT THE INTERNATIONAL LEVEL}

Abstract. Knowledge about roots and family values is a basis for a strong state. A country cannot be respected by outer forces if its citizens are not fond of their originality and do not see the beauty of their own nation. However, the uniqueness of traditions is that they are transformed under the influence of time, what makes them alive. That is why it is not enough for the constituent members of the Russian Federation to open local history museums or to organize exhibitions about national peculiarities in cultural centers in order to build a regional brand. Attempts to represent Russian traditions only through Russian national «sarafan» or accordion dancing look feckless.

Regional branding is a calling card of a region. This is the reason why it has to include information about most innovative vectors and up-dated production, as well as state-of-the-art technology and successors of the local traditions.

Up-to-date understanding of the national traditions can become not only the foundation of regional branding, but also a basis for building up communication in terms of humanitarian cooperation with Russian compatriots as well as foreigners who like Russia, its traditions and values. The more intensively civic institutions develop the humanitarian cooperation, the stronger Russian society (and regions) will be as well as the better quality information about the Russian Federation will be available for our foreign partners.

Keywords: humanitarian cooperation, public diplomacy, region development, traditions, traditional architecture, regional branding 